\title{
Experimental Study on the Thermal Response of PCM Energy Storage Block with Hole Ventilation
}

\author{
Sunqi Zhuang, ${ }^{1}$ Yuan Zhang, ${ }^{2}$ Qin Zhu, ${ }^{1}$ Renqiao Yan, ${ }^{1}$ and Jiapeng He \\ ${ }^{1}$ College of Urban Construction \& Safety Engineering, Nanjing Tech University, Nanjing 210009, China \\ ${ }^{2}$ School of Energy and Power Engineering, Jiangsu University, Zhenjiang 212013, China \\ Correspondence should be addressed to Yuan Zhang; yuanzhangnj@126.com
}

Received 26 November 2014; Accepted 11 January 2015

Academic Editor: João M. P. Q. Delgado

Copyright (c) 2015 Sunqi Zhuang et al. This is an open access article distributed under the Creative Commons Attribution License, which permits unrestricted use, distribution, and reproduction in any medium, provided the original work is properly cited.

\begin{abstract}
Under the condition of Nanjing, the effect by the velocity variation of night ventilation on the thermal response of the south wall built by phase-change materials (PCMs) blocks with different configurations has been investigated and analyzed. It shows that the thermal performance when the PCM is placed nearby inner side in hollow block is better than that of the outer side. Meanwhile, the maximum amplitude of the temperature on the interior surface when the PCM is placed at the inner side is $58.3 \%$ higher than that of the outer side. The optimal flow velocity of both $\mathrm{A}$ and B is $2 \mathrm{~m} / \mathrm{s}$. Meanwhile, the minimum amplitudes of the temperature on the interior surface are $1.74^{\circ} \mathrm{C}$ and $3.72^{\circ} \mathrm{C}$ as well as the retardation coefficients are $8 \mathrm{~h}$ and $7 \mathrm{~h}$. Compared to the structure configuration without ventilation, the heat flow was reduced $38.2 \%$ and $29.3 \%$, respectively, and the equivalent heat resistance increased by $115.8 \%$ and $88.6 \%$.
\end{abstract}

\section{Introduction}

Phase-change materials used in building envelope provides a new way for energy saving. However, seeking suitable PCM that completely fit the local climate conditions is a thorny problem. To make the PCMs play a better role, more and more night ventilation techniques are used.

At present, scholars have studied a lot on PCM powered by night ventilation. The indoor comfort affected by the natural ventilation at night with and without PCM has been studied experimentally by Arkar and Medved [1]. The research showed that the thermal comfort with PCM was better and when the phase-transition temperature was from $20^{\circ} \mathrm{C}$ to $22^{\circ} \mathrm{C}$, it was more suitable for ventilation under its working condition. But they did not combine PCM with building envelope. Raj and Velraj [2] simulated the phasechange wall with night ventilation by CFD software. The phase-change wall was piled up by honeycomb block. The results showed that the phase-change honeycomb block can make the night cold air stay longer and thus improve the heat transfer. The effect was remarkable especially when the ventilation flow rate was $1 \mathrm{~m} / \mathrm{s}$. But the ventilation holes of honeycomb block are round holes, and they did not discuss the influence on thermal response of rectangular holes. Jaworski [3] placed PCM in office building's roof and combined with night ventilation. The results showed that the night ventilation not only brings better indoor comfort, but also makes PCM in the best condition and plays the biggest role. At present, domestic studies are still in the initial stage, but a lot of achievements have been made. Wang [4] studied solar ventilation wall combined with PCM in hot summer and cold winter zones. She analyzed the ventilation effects in summer daytime but did not discuss the cold storage situation of night ventilation. Zhang [5] studied using effect of different PCM combined with night ventilation in Xian by theory calculation and experimental research, put forward the shortcomings of the existing ventilation, and improved them. But it may be more intuitive to comment from the wall or indoor thermal response.

Therefore, this paper takes the condition of Nanjing as an example, selecting the solar-air temperature $T_{\text {out }}$ that is determined by outdoor air temperature and solar radiation as the meteorological parameters. The thermal response performance of different structure of phase change energy 
TABLE 1: The list of construction of external south wall.

\begin{tabular}{lccc}
\hline Name & Outer hole & $\begin{array}{c}\text { Middle } \\
\text { hole }\end{array}$ & Inner hole \\
\hline Structure A & Air & $\begin{array}{c}\text { Air } \\
\text { vent }\end{array}$ & $\begin{array}{c}\text { Gypsum-based } \\
\text { phase-change-board }\end{array}$ \\
Structure B & $\begin{array}{c}\text { Gypsum-based } \\
\text { phase-change-board }\end{array}$ & $\begin{array}{c}\text { Air } \\
\text { vent }\end{array}$ & Air \\
\hline
\end{tabular}

storage masonry wall is studied with different night ventilation velocity by experiments.

\section{The Necessity of Night Ventilation}

The hottest day in summer Nanjing is "the dog" period. The heat that PCMs have absorbed during the day cannot be released completely at night under sustained high temperature. This will reduce the performance of PCM in the next day. With the heat piled up, PCM will liquefy completely and the capacity of latent heat storage will also disappear. The capacity of release heat will become stronger by night ventilation. It can maintain the absorbed heat during the day equal to the released heat at night maximally. The operating cycles of PCM can be extended.

\section{Physical Model}

The studied physical model is the south wall in summer Nanjing. The area of the model is $1 \mathrm{~m}^{2}$ and its height, width, and thickness are $1 \mathrm{~m}, 1 \mathrm{~m}$, and $0.19 \mathrm{~m}$, respectively. In order to prevent the leakage of PCM in the experiment, we manufactured gypsum-based phase-change-boards (GPCBs) with the mass ratio of the PCM and gypsum mixed by $1: 1.3$ in proportion. The PCM is decanoic acid and the wall is piled up by hollow blocks with three rows of holes (Figure 1). The block with GPCBs is showed in Figure 2. Placed GPCBs in inner holes or outer holes (Figure 1) of the block can form two different structure configurations of external walls structure (Table 1).

3.1. Physical Parameters of Wall. Table 2 lists all material properties which have been used.

3.2. Outdoor Calculating Temperature. That which works on the surface of south wall is the solar radiation besides the air temperature. Therefore, the solar-air temperature is taken as the outdoor calculating temperature. The hottest days in the summer of Nanjing are in the "the dog" period. Therefore, we take July 20 th to 24 th as the calculation temperature. Meteorological parameter is selected from Dedicated meteorological database of the analysis for building thermal environment in China [6].

\section{Experiment}

4.1. Experimental Principle and Equipment. The JW-I thermoresistance detector device is shown in Figure 3. The left

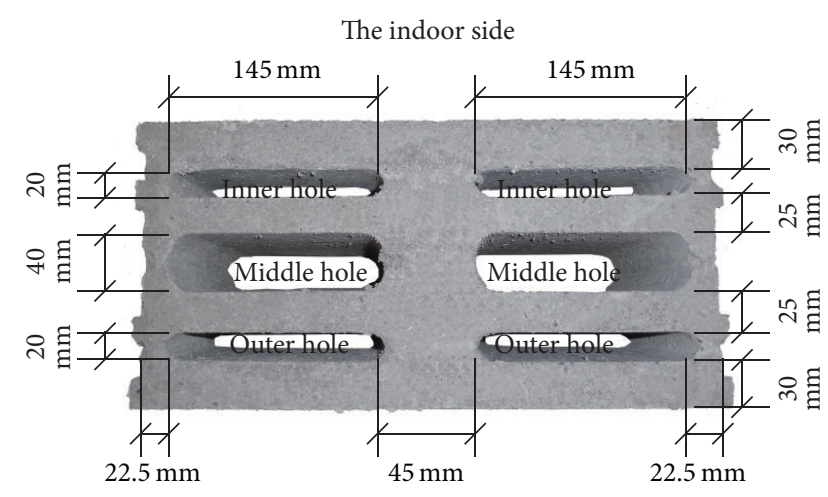

The outdoor side

Figure 1: The actual object and size of block.

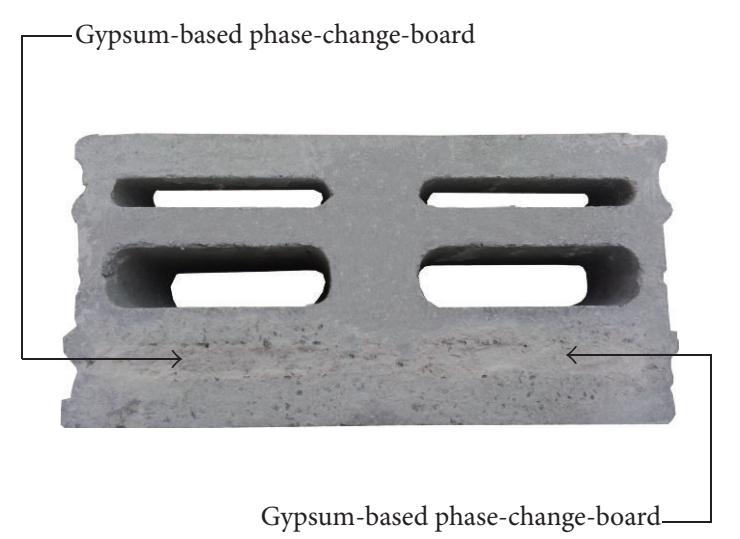

FIgURE 2: The actual object of block with GPCBs.

box is cold box and the right one is hot box. They are used to simulate the indoor environment and outdoor environment, respectively. The frame of the test-piece in this device also can be seen in Figure 3. The model of control device of programming is XMT-4000B. The measuring accuracy is level $0.2( \pm 0.2 \% \mathrm{FS})$. The data acquisition instrument, which measurement error is $\pm 2.1^{\circ} \mathrm{C}$, is used in this experiment and the model is Agilent 34970A.

The hot box method was used in the experimental study. The outdoor environment was simulated by the control device of programming. During the experiment, the frames of the boxes were thermally insulated.

Thermocouples were used for monitoring the temperature of the inner and the outer surfaces of wall and the phase-change room, as shown in Figure 4. The type of the thermocouples is $T$ type. The measurement range is $-50^{\circ} \mathrm{C} \sim$ $100^{\circ} \mathrm{C}$, the accuracy grade is 0.2 , and the resolution ratio is $0.1^{\circ} \mathrm{C}$. At the bottom and top sides of the phase-change wall, there are an air inlet and an air outlet. The air inlet is connected with blower. The start-stop of blower is controlled by circuit feedback system. When the outdoor temperature is lower than the average temperature of the ventilated hole inner surface, the blower begins to work. Conversely, the blower does not work. The experimental device consists of an isolated system. In order to reduce the influence of the 
TABLE 2: The physical parameters of materials.

\begin{tabular}{|c|c|c|c|c|c|c|c|}
\hline $\begin{array}{l}\text { Material } \\
\text { name }\end{array}$ & $\begin{array}{l}\text { Density } \\
\rho / \mathrm{kg} \cdot \mathrm{m}^{-3}\end{array}$ & $\begin{array}{l}\text { Specific heat } \\
C_{p} / \mathrm{J} \cdot \mathrm{kg}^{-1} \cdot \mathrm{K}^{-1}\end{array}$ & $\begin{array}{l}\text { Thermal } \\
\text { conductivity } \\
\lambda / \mathrm{W} \cdot \mathrm{m}^{-1} \cdot \mathrm{K}^{-1}\end{array}$ & $\begin{array}{l}\text { Latent heat } \\
\Delta H / \mathrm{kJ}^{-} \mathrm{kg}^{-1}\end{array}$ & $\begin{array}{c}\text { Phase-transition } \\
\text { temperature of } \\
\text { solid } \\
t_{s} /{ }^{\circ} \mathrm{C}\end{array}$ & $\begin{array}{c}\text { Phase-transition } \\
\text { temperature of } \\
\text { liquid } \\
t_{q} /{ }^{\circ} \mathrm{C}\end{array}$ & $\begin{array}{c}\text { Phase-change } \\
\text { radius } \\
\omega /{ }^{\circ} \mathrm{C}\end{array}$ \\
\hline Block & 1365 & 960 & 0.6 & 1 & 1 & 1 & 1 \\
\hline Air & 1.225 & 1006.43 & 0.0242 & I & I & I & I \\
\hline GPCBs & $\begin{array}{l}\text { Change with } \\
\text { temperature }\end{array}$ & $\begin{array}{l}\text { Change with } \\
\text { temperature }\end{array}$ & $\begin{array}{l}\text { Change with } \\
\text { temperature }\end{array}$ & 153 & 19.48 & 27.72 & 4.12 \\
\hline
\end{tabular}

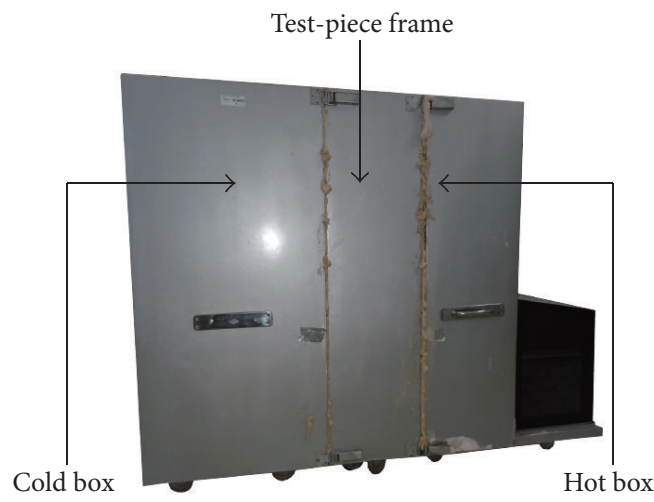

Figure 3: The picture of the actual object of JW-I.

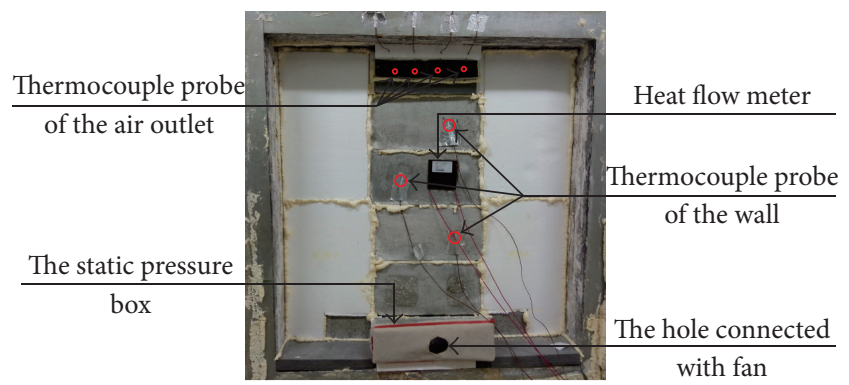

FIGURE 4: The arrange picture of thermocouple and heat flow meter.

external environment on the results, the joint between the cold-hot box and test-piece frame was filled by polyurethane foam. Figure 5 is experimental principle.

4.2. The Conditions of Intermittent Ventilation. When the inlet temperature was lower than the average temperature of the ventilated hole wall, the ventilation can work with the best effect. At this time, the storage heat of PCM can be released quickly. Therefore, in the process of experiment, the thermocouples were arranged at the air inlet and outlet. When the condition was satisfied, the fan was switched on.

4.3. Indoor Temperature Analysis. Figure 6 displays the comparison of the temperature fluctuation of the indoor temperature $T_{\text {in }}$ in these two structures under different ventilation. From Figures 6(a) and 6(b), we can find several common points: for the case of ventilation inside the wall, the average

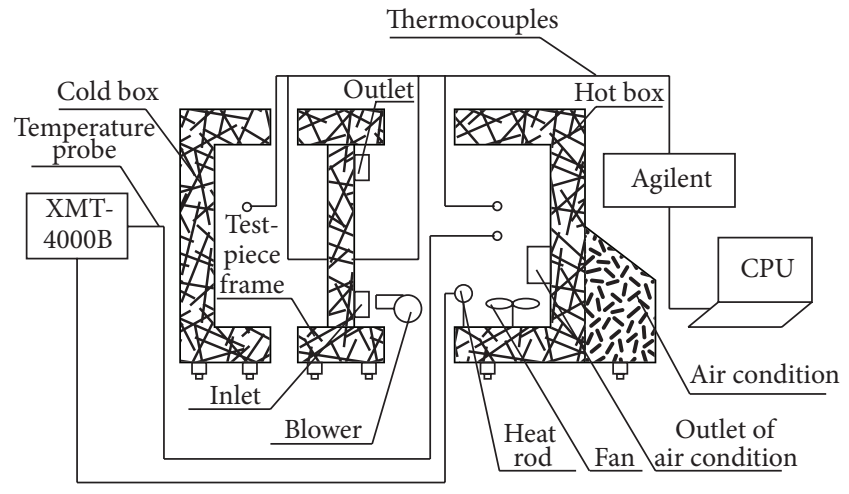

FIGURE 5: The picture of experimental principle.

temperature on the interior surface of wall is apparently lower than the case without ventilation. And no matter how much the ventilation velocity is, the indoor temperature amplitude of these two structures $\left(3.5^{\circ} \mathrm{C} \sim 4.5^{\circ} \mathrm{C}\right)$ reduces greatly comparing with the sol-air temperature of the outdoor environment, and the peak is also delayed. The even temperature fluctuation can bring better comfort and reduce the start-stop time of air condition. It can reduce energy consumption. The delay of the temperature peak reduces the electricity peak. At the same time, in response to the national "peak valley" policy, it can save money. The decreasing amplitude of inner surface temperature is $5^{\circ} \mathrm{C}-8^{\circ} \mathrm{C}$ when it is ventilating. As the velocity increases, the temperature amplitude on the interior surface and the drop rate of the average temperature both reduce gradually, and the higher velocity brings more consumption of fan energy. Generally, the optimal flow rate of structure A is $2 \mathrm{~m} / \mathrm{s}$, and the minimum amplitude of wall surface is $1.74^{\circ} \mathrm{C}$. Meanwhile, the maximum coefficient delay is $8 \mathrm{~h}$. The optimal velocity of structure B is $2 \mathrm{~m} / \mathrm{s}$ too. Minimum amplitude of wall surface is $3.72^{\circ} \mathrm{C}$, and maximum coefficient delay is $7 \mathrm{~h}$. However, the two kinds of structures are quite different. For structure B, the PCM is placed outside, so it will melt quickly and lose its function in the influence of outdoor integrated temperature, which makes the meaning of existence to PCM reduce greatly. The maximum temperature amplitude on the interior surface is up to $6.58^{\circ} \mathrm{C}$. For the structure A; the PCM is placed inside; therefore, the PCM is influenced a little by the outdoor integrated temperature, so it can play an important role in the function of thermal storage, making low fluctuation of wall surface temperature. The maximum temperature amplitude on the interior surface 


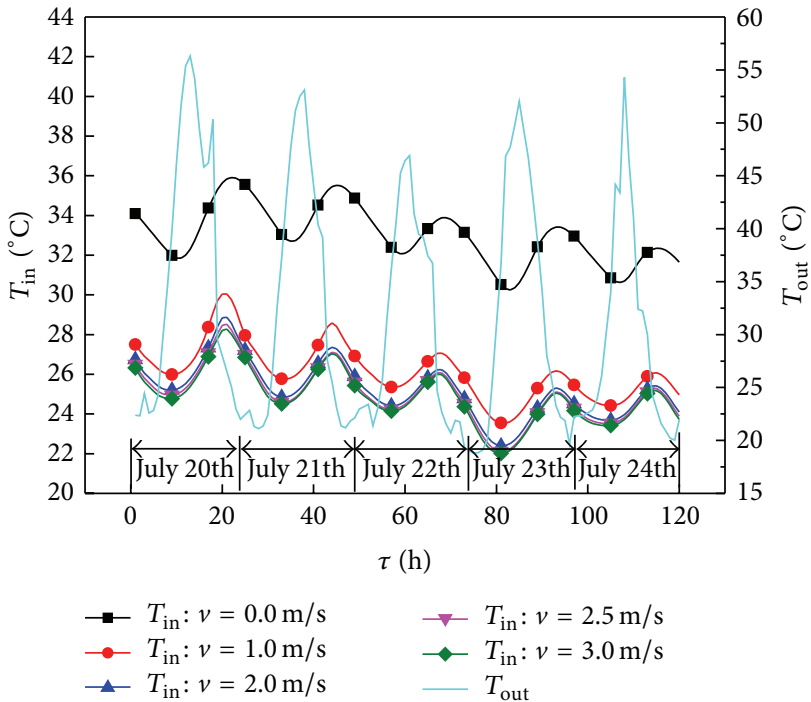

(a) Structure A

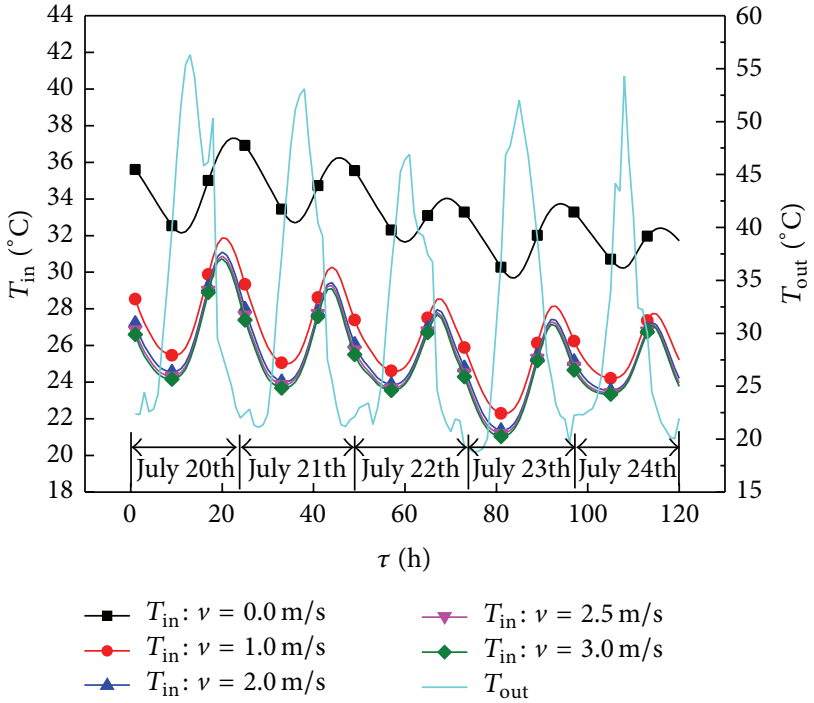

(b) Structure B

FIGURE 6: Contrast pictures of temperature of inner surface in different structure with several velocities.

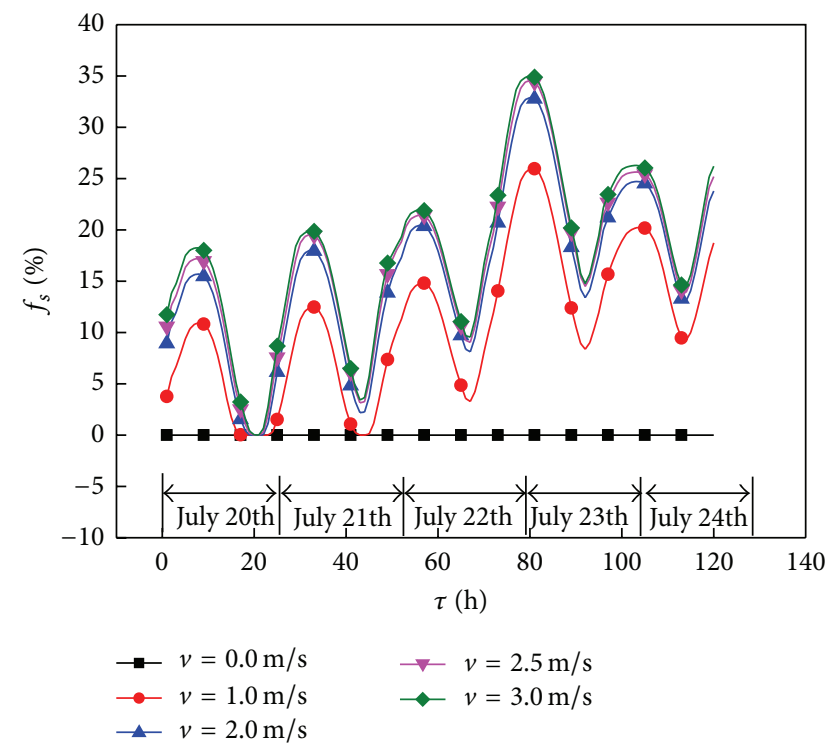

(a) Structure A

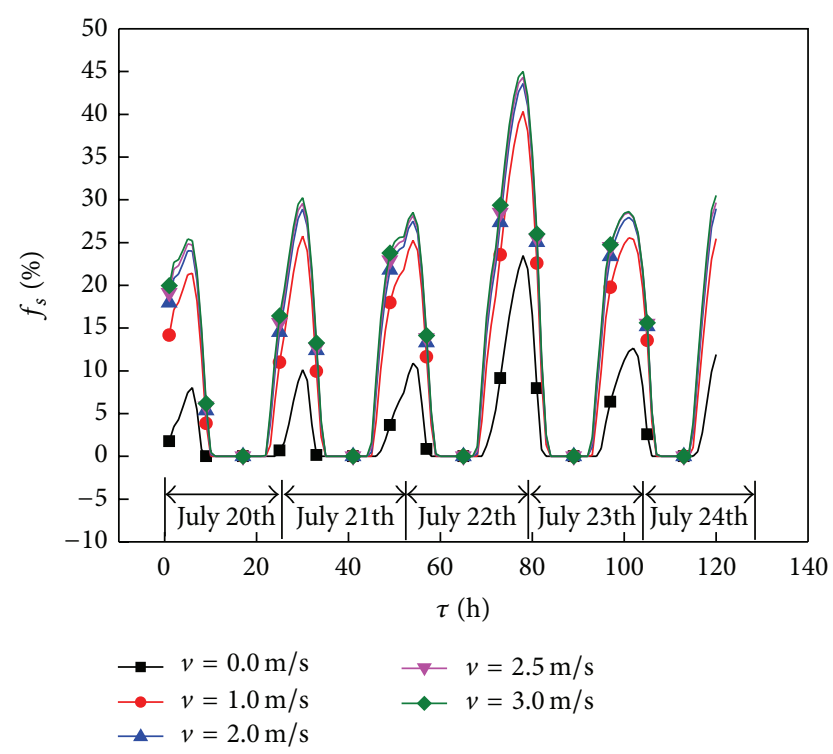

(b) Structure B

FIGURE 7: Contrast pictures of solid fraction of inner surface in different structure with several velocities.

of structure A wall is $3.84^{\circ} \mathrm{C}$, which is $58.3 \%$ of the structure B wall.

4.4. The Solid Fraction of PCMs. When we measure the temperature of the PCM in the experiment, according to (1), we can calculate the solid fraction of PCM. Solid fraction is the proportion of solid PCM in whole PCM. When $f_{s}=0$, PCM is in liquid phase. When $f_{s}=1$, PCM is in solid phase. When $0<f_{s}<1$, PCM is in phase change zone [7]. Consider

$$
f_{s}=\frac{t_{q}-t}{t_{q}-t_{s}},
$$

where $f_{s}$ is the solid fraction of PCM, \%; $t$ is phase change temperature, ${ }^{\circ} \mathrm{C}$; $t_{q}$ is the temperature of liquid phase, ${ }^{\circ} \mathrm{C}$; and $t_{s}$ is the temperature of solid phase, ${ }^{\circ} \mathrm{C}$.

Figure 7 demonstrates the solid fraction of the PCM under different structures and flow rates. From Figure 7, it can be found that, without ventilation, the solid fraction of the PCM in structure A is attempted to be zero after the temperature wave reached stable, which indicates that the PCM is to be completely liquefied. It results from the delay and attenuation of the temperature wave. Compared to structure A, the PCM of structure B is more effective, but, due to the response of outdoor solar-air temperature, 


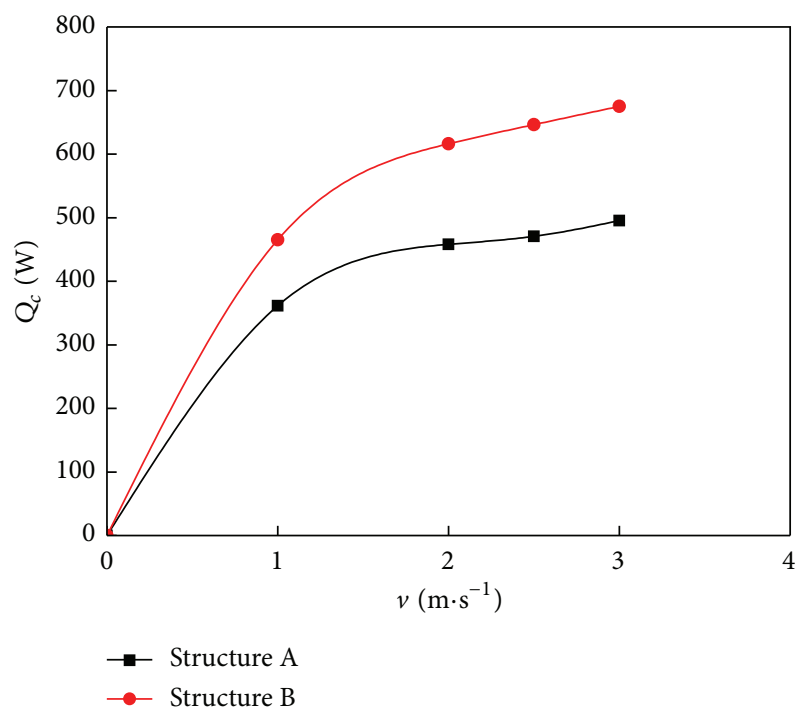

FIGURE 8: Contrast picture of quantity of heat with ventilation.

the phase changes quickly. It leads the PCM to be completely liquefied. With the increase of velocity, the PCM of structure A can be in a phase transition all the time, keeping the best status. While structure B is not so stable, sometimes PCM is completely liquefied with high utilization. We can draw the same conclusion as Figure 6 , the best velocity of both structure A and structure B is $2 \mathrm{~m} / \mathrm{s}$.

4.5. The Analysis of Removed Heat by Ventilation and Equivalent Thermal Resistance. Figure 8 displays the removed heat by mechanical ventilation from July 20 th to July 24 th. Analyzing Figure 8 we can know both structure A and structure B, and, with the increase of velocity, the removed heat becomes more and more. But the growth of the removed heat is becoming smaller. On the contrary, the increase of flow rate will bring greater fan energy consumption. Thus, we can draw the same conclusion as Figure 6: the best velocity of both structure $A$ and $B$ is $2 \mathrm{~m} / \mathrm{s}$. In this case, the heat removed by mechanical ventilation $Q_{C}$ is $457.8 \mathrm{~W}$ and $616.3 \mathrm{~W}$. Compared with no ventilation, $38.2 \%$ and $29.3 \%$ of heat which flowed into indoor are reduced, respectively.

Figure 9 is the comparison picture of equivalent thermal resistance $R$ of hollow building blocks with two kind structures at different flow velocity. Similar conclusions can be drawn from Figure 9: with the increase of velocity, equivalent thermal resistance of these two kinds of structures is increasing, but the equivalent thermal resistance increase rate has decreased. So there is an optimum flow rate. Either structure A or structure B is $2 \mathrm{~m} / \mathrm{s}$. With comparison of no ventilation, equivalent thermal resistance structure of $\mathrm{A}$ and $\mathrm{B}$ is increased by $115.8 \%$ and $88.6 \%$, and the equivalent thermal resistance of a substantial increase is mainly due to the reasonable ventilation. At the same velocity, the equivalent thermal resistance of structure $\mathrm{A}$ is larger than structure of $\mathrm{B}$. The main reason for this can be attributed to the utilization rate of PCM. The utilization efficiency is lower

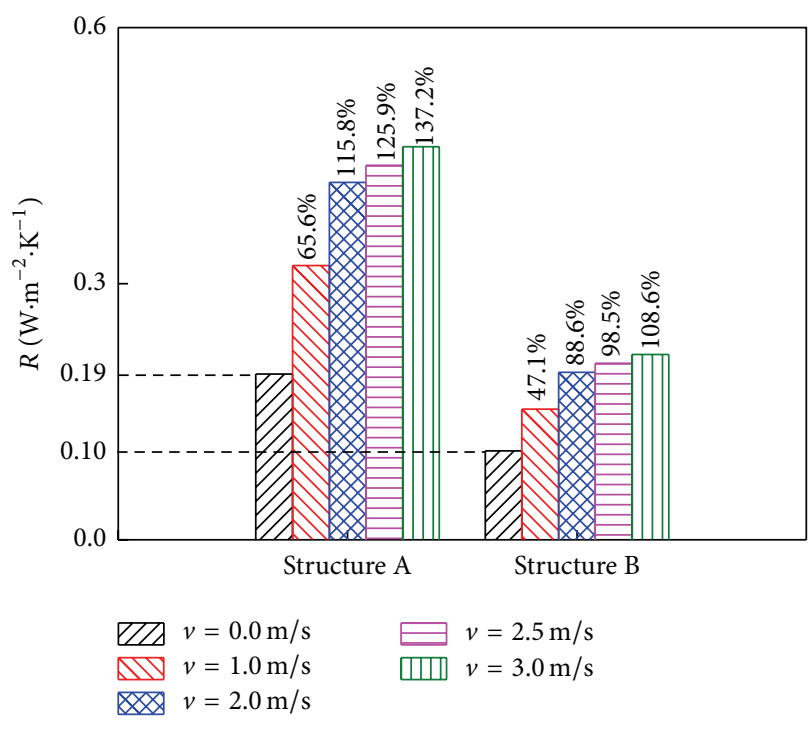

FIGURE 9: Contrast picture of equivalent thermal resistance.

when PCM is arranged outside. The status will be larger in a state of pure solid or liquid. This will lead to the increase of thermal conductivity and reduction equivalent thermal resistance.

\section{Conclusions}

This paper takes the south wall of buildings in Nanjing as physical model, selecting the outdoor solar-air temperature as calculating temperature during the period of Nanjing "the dog" period from July 20th to July 24 th. The indoor thermal response in different ventilation with PCM inside or outside of the three rows of hollow blocks has been experimentally studied and analyzed. It can draw the following conclusions.

(1) When the phase change materials are placed at the inner row of the three rows in the hollow block, the thermal performance is better. The maximum temperature amplitude on the surface of wall temperature is $3.84^{\circ} \mathrm{C}$ when the PCM is at the inner side, only $58.3 \%$ of that at the outer side.

(2) Either structure A or structure B, with the increase velocity of the ventilation flow, the temperature amplitude on the inner surface of wall, and the drop rate of wave base value are reduced gradually. There is an optimum flow rate.

(3) The optimal velocity of structure A and structure $\mathrm{B}$ is for both $2 \mathrm{~m} / \mathrm{s}$, while the minimum amplitude and maximum delay coefficient of the surface temperature inside the wall are $1.74^{\circ} \mathrm{C}, 8 \mathrm{~h}$, and $3.72^{\circ} \mathrm{C}$, $7 \mathrm{~h}$, respectively. The heat removed by ventilation and the equivalent thermal resistance are, respectively, $457.8 \mathrm{~W}, 616.3 \mathrm{~W}$ and $0.41\left(\mathrm{~m}^{2} \cdot \mathrm{K}\right) / \mathrm{W}, 0.19\left(\mathrm{~m}^{2} \cdot \mathrm{K}\right) / \mathrm{W}$, comparing with that without venation. The heat that transports into the indoor, respectively, reduces to $38.2 \%$ and $29.3 \%$. The equivalent thermal resistances increase by $115.8 \%$ and $88.6 \%$, respectively. 


\section{Conflict of Interests}

The authors declare that there is no conflict of interests regarding the publication of this paper.

\section{Acknowledgments}

This work was financially supported by the Natural Science Foundation of China (no. 51508232), the Natural Science Foundation of Jiangsu Province (no. BK20150521), the Jiangsu Province Postdoctoral Science Foundation (no. 1501106B), the Scientific Research Starting Foundation for Advanced Talents of Jiangsu University (no. 15JDG049), and the 12th Five Year National Science and Technology Support Key Project of China (no. 2011BAE14B06).

\section{References}

[1] C. Arkar and S. Medved, "Free cooling of a building using PCM heat storage integrated into the ventilation system," Solar Energy, vol. 81, no. 9, pp. 1078-1087, 2007.

[2] V. A. A. Raj and R. Velraj, "Heat transfer and pressure drop studies on a PCM-heat exchanger module for free cooling applications," International Journal of Thermal Sciences, vol. 50, no. 8, pp. 1573-1582, 2011.

[3] M. Jaworski, "Thermal performance of building element containing phase change material (PCM) integrated with ventilation system - an experimental study," Applied Thermal Engineering, vol. 70, no. 1, pp. 665-674, 2014.

[4] Y. X. Wang, Adaptation of solar ventilation combined with phase change wallboard in hot summer and warm winter region [dessertation], South China University of Ethnology, Guangzhou, China, 2012.

[5] P. Zhang, Suitability of phase change materials for night ventilation cooling technique [M.S. thesis], Xian University of Architecture and Technology, Xi'an, China, 2013.

[6] A. Y. Xiong and F. T. Song, Dedicated Meteorological Database of the Analysis for Building Thermal Environment in China, China Architecture \& Building Press, Beijing, China, 1st edition, 2005.

[7] X. X. Kong, The Application of Finite Element in Heat Transmission Science, Science Press, Beijing, China, 1998. 

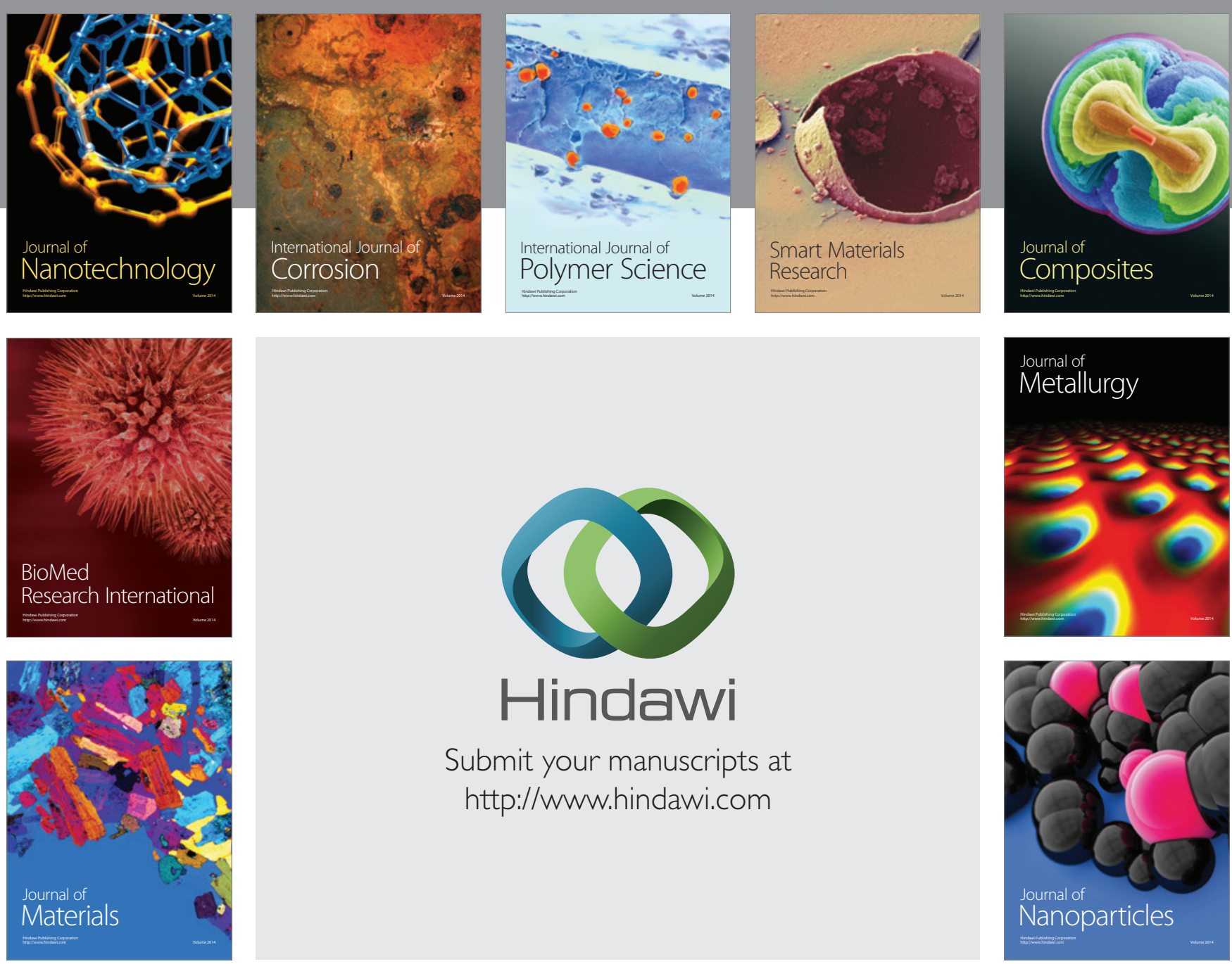

Submit your manuscripts at http://www.hindawi.com
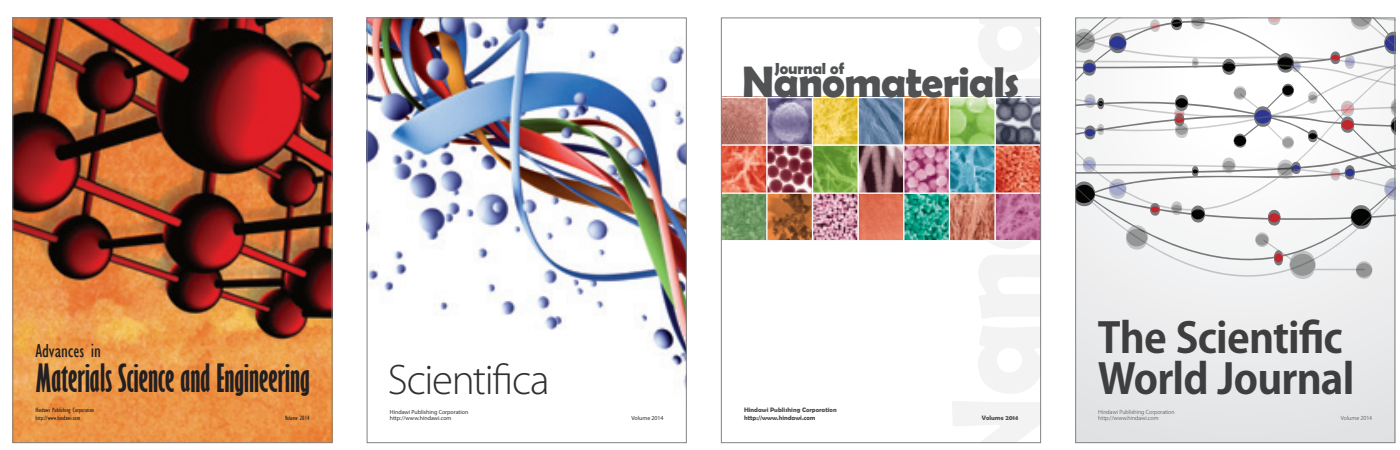

\section{The Scientific World Journal}
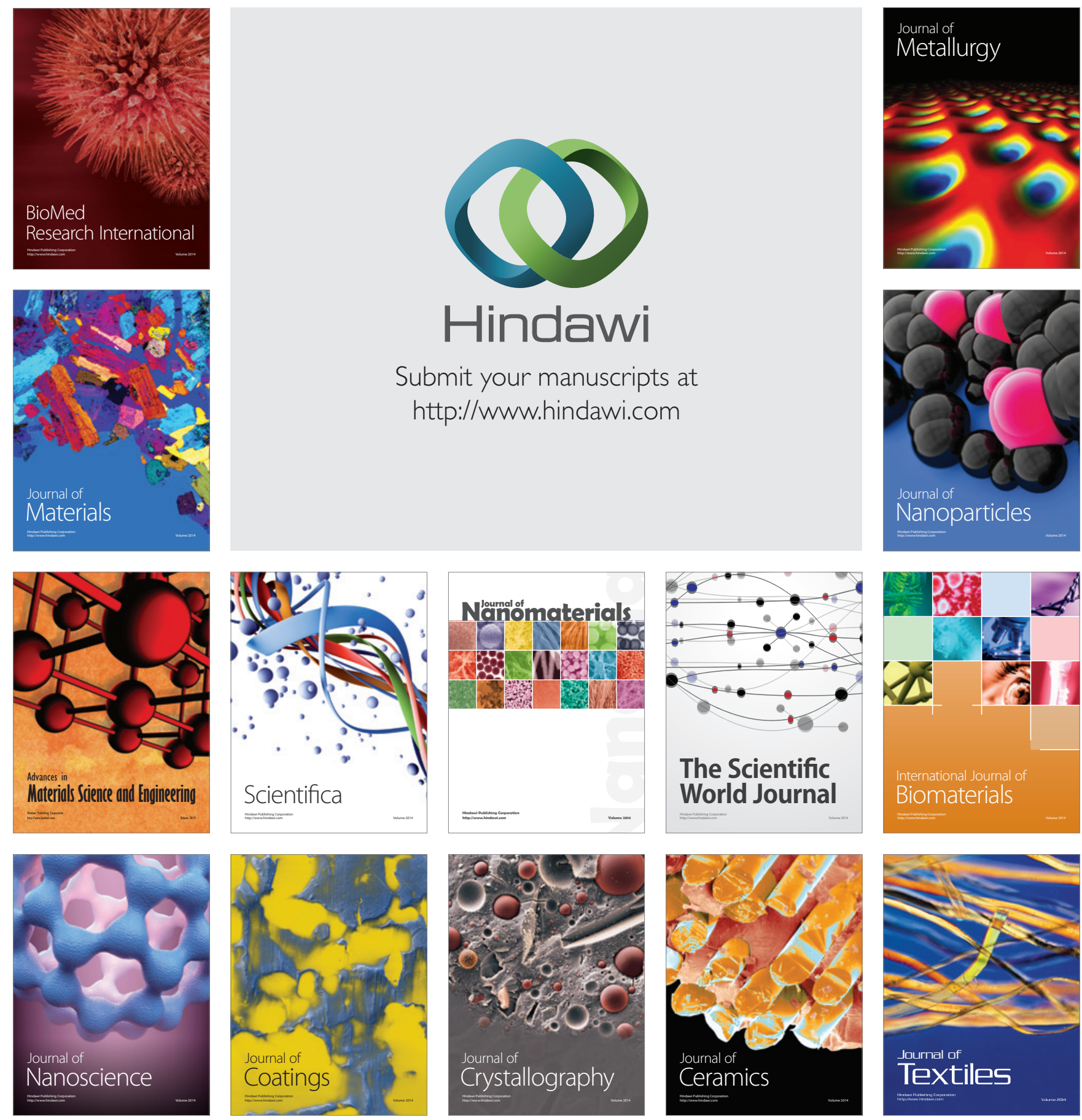